\title{
A Rare Case of Gestational Diabetes Mellitus Who Delivered 6 Kg Baby.
}

\author{
Dr.Satyavathi Maluchuru Asst.Professor, Dr.M.Sailaja Prasad Professor, \\ Dr.K.Saraswati Professor, Dr.Supriya.
}

\section{Introduction}

Gestational Diabetes Mellitus (GDM) is an important public health problem given its high prevalence and its association with adverse maternal and fetal outcomes. Recent evidence has confirmed that the risk of adverse outcomes is a continuum, increasing as maternal blood glucose levels rise [1] furthermore, women with prior GDM are a high-risk group for the future development of diabetes, metabolic syndrome and cardiovascular disease[2] GDM has adverse outcomes of pregnancy including preeclampsia, caesarean section rates(which varies from 30-40\%)perinatal mortality(2-fold increased),birth defects, metabolic complications in Neonates and morbidity associated with subsequent childhood obesity. Furthermore, the recurrence risk with future pregnancies has been reported as high as 68\% [3] and 26\%[4] risk of developing type two diabetes at 15 years of follow up.

\section{Case study}

A 29-year-old G4P2L2 Ab1 has antenatal checkups from 5th months (20 weeks)of pregnancy in Niloufer Hospital for women and children (Hyderabad, Telangana). According to her, her LMP is on 19/12/2015. She had menstrual cycles of 5 days in 30-45days, irregular, moderate flow. Antenatal ultrasound at 9 weeks was done and according to it, Expected Date of Delivery (EDD) is on 19/9/2016.her mother is diabetic and hypertensive.

\section{Obstetric History}

1ST PREGNANCY:- she had a GDM ,she was on Insulin in 2nd and 3rd trimester. She also gave history of increased blood pressure. She had full term LSCS. Indication being CPD (cephalo pelvic disproportion).Female baby birth weight $-3 \mathrm{~kg}$ without any complications. She was told to have normal blood glucose level after delivery

2nd pregnancy:-had GDM in second trimester. She was on insulin in 2nd and 3rd trimester.

At term, she underwent elective LSCS indication CPD. She had a male baby of $3.5 \mathrm{~kg}$ without any anomalies. Her blood glucose level was normal.

3rd pregnancy:-she had spontaneous abortion at 2 months of gestation.

4th pregnancy:- the women had antenatal checkups in our hospital from 20 weeks onwards. Her body weight was $75 \mathrm{~kg}$, height 5 feet 4 inches. Her LMP is not reliable, hence EDD was calculated from 9 weeks' ultrasound scan and was on 19/9/16.At 20 weeks, her OGTT-201 mg/dl and other routine investigations were within normal range. Blood group O Positive. As her OGTT was high (upper limit is $140 \mathrm{mg} / \mathrm{dl}$ )she was advertised FBS,PLBS and endocrinologist opinion. She was started on (12Uto6U)R-insulin up to 28 weeks. Her blood glucose levels were in normal range. She was advised antenatal checkups once in every 15days.For some personal reasons, the women did not attend our hospital from 28 weeks to 36 weeks of gestation. At 36 weeks, her FBS-163 mg/dl, PLBs $215 \mathrm{mg} / \mathrm{dl}, \mathrm{HbA}_{1} \mathrm{c}-15.7 \%$.Her body weight was $90 \mathrm{~kg}$. She was admission for control of blood sugars, but the women refused to get admitted. She again came to us at 38 weeks. Her blood pressure was 130/90, Fasting Blood sugar was $106 \mathrm{mg} / \mathrm{dl}$. Antenatal ultrasound shows single live fetus, cephalic presentation placenta posterior upper segment. AFI- $32.7 \mathrm{~cm}$ with gestational age of $40 \mathrm{weeks} 2$ days, estimated birth weight $-5282 \mathrm{gm}$. We have decided for elective LSCS, indication being 2 previous LSCS and big baby (macrosomia) we have taken all measures to prevent postpartum hemorrhage. A male baby was born with an APGAR of 9 and 10 at $1 / 5$ minutes, an umbilical artery PH 7.32 and birth weight of $6000 \mathrm{gm}(6 \mathrm{Kg})$.weight of placenta was $11 / 2 \mathrm{~kg}$. There were no intraoperative and post-partum complications. Thorough workup was done to rule out anomalies in the baby and the woman was discharged on 7th postoperative day. 


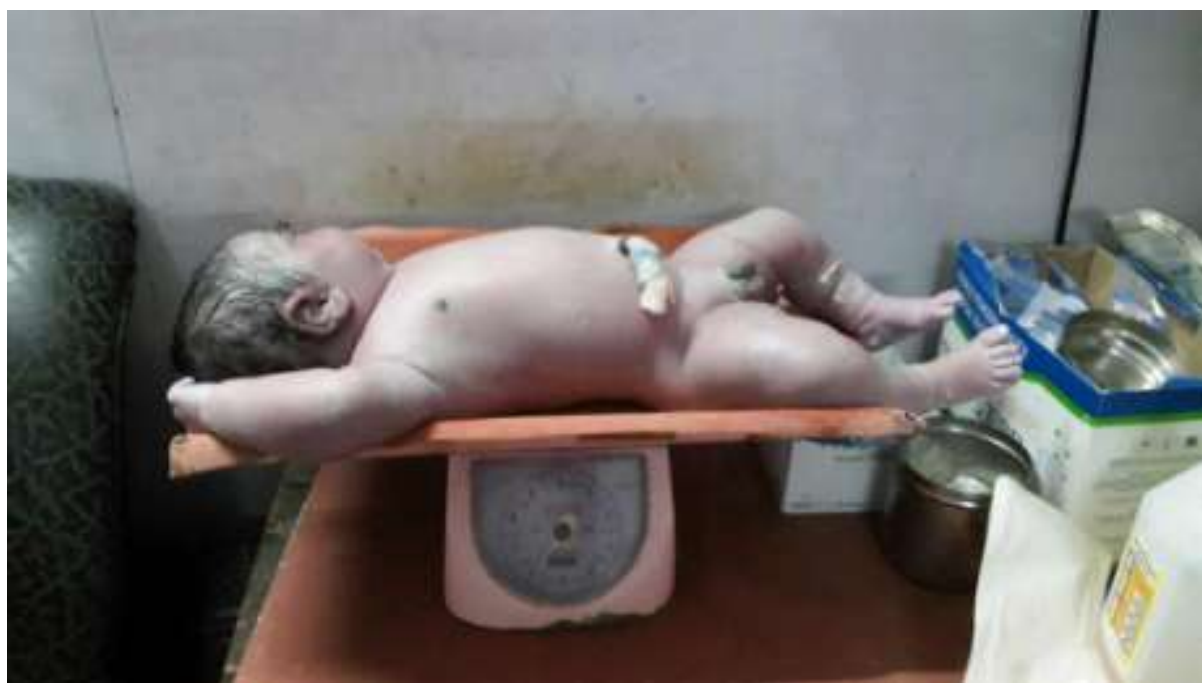

a birthweight of $6 \mathrm{Kg}$ (13.2277 pound)

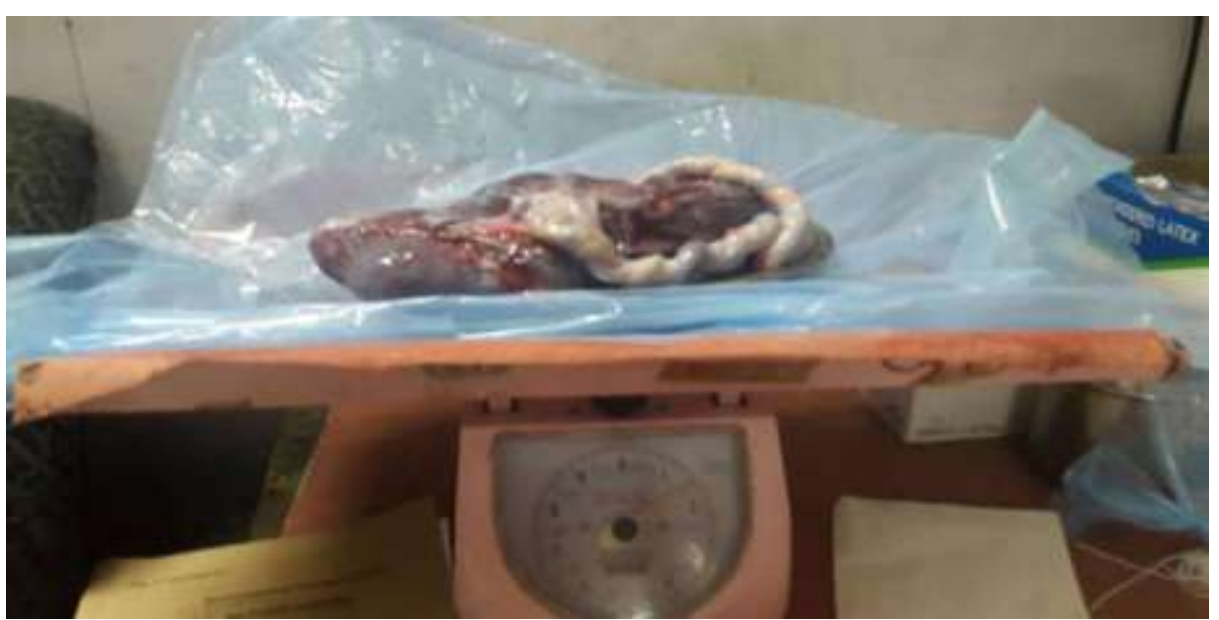

weight of placenta was 1 1/2kg(3.306pound)

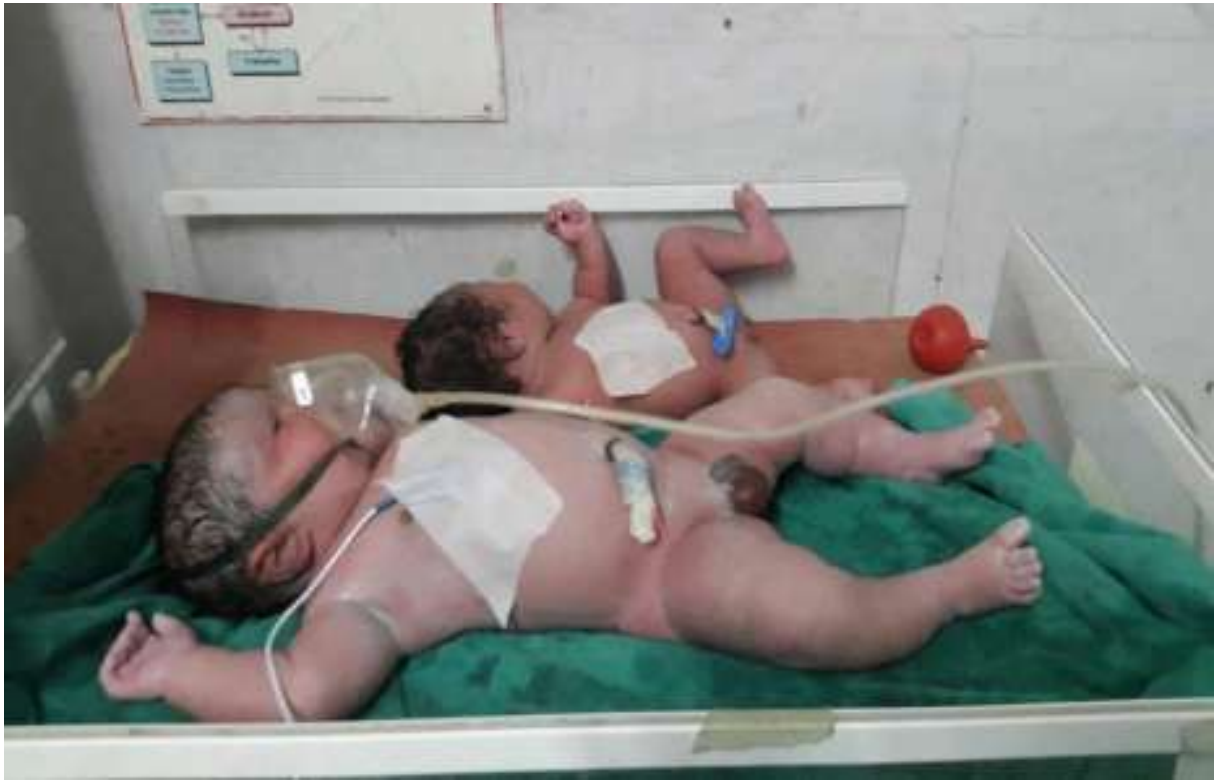

Compared with another baby of weight $2.7 \mathrm{~kg}(6.062$ pound $)$ 


\section{Conclusion}

The detection of GDM can also have important consequences following pregnancy. Women with a prior diagnosis of GDM are at an increased risk for the future development of diabetes, metabolic syndrome and cardiovascular disease. Identification of the seat-risk women permits the implementation of lifestyle modifications and a targeted follow-up that would not be applied when GDM goes undetected. The timely action taken in screening all pregnant women for glucose intolerance, achieving euglycemia and ensuring adequate nutrition may prevent all probabilities, the vicious cycle of transmitting glucose intolerance from one generation to another.

\section{References}

[1]. HAPO Study Cooperative Research Group,Metzger BE,Lowe LP,Dyer AR,Trimble ER,et al.(2008)hyperglycemia and adverse pregnancy outcomes.N Engl J Med 358:1991-2002.

[2]. NoctorE,Crowe C,Carmody,Kirwan,O'DeaA,etal.(2015)ATLANTIC DIP:

[3]. prevalence of metabolic syndrome and insulin resistance in women with previous gestational diabetes mellitus by International Association of Diabetes in Pregnancy Study Group criteria.Acta Diabetol 52:153-160.

[4]. Spong CY,Guillermo,Kuboshi eJ,etal.Recurrence of gestational Diabetes Mellitus:identification frisky factors.Am J Perinatol.1998;15(1):29-33.

[5]. LeeAJ,HiscockRJ,WeinP.Gestational diabetes mellitus:clinical predictors and long term risk of developing type 2 diabetes:a retrospective cohort study using survival analysis.Diabetes Care.2007;30:878-83.

[6]. Schaefer-Graf UM,Kjos SL,Fauzan,Bühling KJ,Siebert G,etal.(2004)A Randomized Trial Evaluating a Predominantly Foetal Growth-Based Strategy to Guide Management of Gestational Diabetes in Caucasian Women.Diabetes Care 27:297-302

[7]. American Diabetes Association(2015)Classification and Diagnosis diabetes.Diabetes Care 38:8-16

[8]. Metzger BE,Coustan DR.Summary and recommendations of the fourth international workshop-conference on gestational diabetes mellitus:the organizing committee.Diabetes Care.1998;21(Suppl.2):B161-7.

[9]. National diabetes data group Diabetes in America 2nd Edition,Harris M(editor).Bethesda,MD:National Institutes of Health;1995.

[10]. Subburaj VK.Secretary to government of India With reference to health and Family Welfare(P)Department Letter(D)No.356;2007.

[11]. International Association of Diabetes and Pregnancy Study Groups Consensus Panel, Metzger BE, Gabbe SG, Persson B, Buchanan TA,et al.(2010)International Association of Diabetes and Pregnancy Study Groups recommendations on the diagnosis and classification hyperglycaemia in pregnancy.Diabetes Care 33:676-682.

[12]. DuránA,Saenz'S,Torrejon M,Bourdieu,delValle,etal.(2014)

[13]. Introduction of IADPSG criteria for the screening and diagnosis of gestational diabetes mellitus results in improved pregnancy outcomes at a lower cost in a large cohort pregnant women:The St Carlos Gestational Diabetes Study.Diabetes Care 37:2442-2450.

[14]. Crowther CA,Hiller JE,Moss J,etal.Effect of treatment of gestational diabetes mellitus on pregnancy outcomes.N Engl J Med.2005;352:2477-86. 